\title{
A portable inhalational induction device provides co-operative induction of anaesthesia in preanaesthetic area for children
}

\author{
Mi-Ja Yun ${ }^{1}$, Hyo-Seok Na ${ }^{1}$, Young Duck Shin², Jun-Sung Han², Jung-Won Hwang ${ }^{1}$, Chong Soo Kim³ , \\ and Jin $\mathrm{Ho} \mathrm{Bae}^{2}$ \\ Department of Anesthesiology and Pain Medicine, ${ }^{1}$ Seoul National University Bundang Hospital, Seongnam, ${ }^{2}$ Chungbuk National \\ University College of Medicine, Cheongju, ${ }^{3}$ Seoul National University Boramae Hospital, Seoul, Korea
}

Background: We introduce a new, simple portable inhalational induction device (PD) that provides co-operative inhalational induction of anaesthesia using $\mathrm{N}_{2} \mathrm{O}$ and subsequent sevoflurane in the preanaesthetic induction area in children.

Methods: Forty-five children (30 to 94 months old age, $<35 \mathrm{~kg}$ ) who were scheduled to undergo simple operations were assigned randomly to one of three regimens. Patients were encouraged by their parents to inhale $\mathrm{N}_{2} \mathrm{O}$ followed by sevoflurane ( $\mathrm{PD} \mathrm{N}_{2} \mathrm{O}$-sevo group) or sevoflurane (PD sevo group) using a portable inhalational induction device in the preanaesthetic induction area until they were unable to respond to their names. They were then transferred to the operating room while maintaining inhalation of sevoflurane via the device. The control group underwent conventional inhalational induction in the operating room with the parents in attendance.

Results: Patients in the $\mathrm{PD} \mathrm{N}_{2} \mathrm{O}$-sevo group had a higher co-operative inhalation frequency than the patients in the $\mathrm{PD}$ sevo or the control group. Anaesthesia induction in the $\mathrm{PD} \mathrm{N}_{2} \mathrm{O}$-sevo and the PD sevo groups were faster than in the control group. Parent satisfaction score (0-100) was higher for the $\mathrm{PD}_{2} \mathrm{O}$-sevo group than for the control group. Conclusions: A new portable inhalational induction device allows faster induction in co-operation with parents present in the preanaesthetic induction area compared to conventional inhalational induction in the unfamiliar operating room with the parents in attendance. (Korean J Anesthesiol 2010; 58: 521-526)

Key Words: Inhalation induction, Nitrous oxide, Potable instrumentation, Sevoflurane.

Received: March 2, 2010. Revised: 1st, March 10, 2010; 2nd, March 30, 2010. Accepted: April 8, 2010.

Corresponding author: Jin Ho Bae, M.D., Department of Anesthesiology and Pain Medicine, Chungbuk National University College of Medicine, 62, Gaesin-dong, Heungdeok-gu, Cheongju 361-711, Korea. Tel: 82-43-269-6233, Fax: 82-43-272-0264, E-mail: jhbae@chungbuk.ac.kr This work was supported by the research grant of the Chungbuk National University in 2008.

(c) This is an open-access article distributed under the terms of the Creative Commons Attribution Non-Commercial License (http:// creativecommons.org/licenses/by-nc/3.0/), which permits unrestricted non-commercial use, distribution, and reproduction in any medium, provided the original work is properly cited. 


\section{Introduction}

Sevoflurane is commonly used for inhalational induction of anaesthesia in children without intravenous (i.v.) access $[1,2]$. However, inhalational induction of preschool children without i.v. access is often difficult because of fear and anxiety concerning unfamiliar environment of operating room, mask inhalation, immature reasoning and limited coping skills.

The oral premedication of benzodiazepine can be used to reduce preoperative anxiety for mask induction but it also could cause arousal distress or delayed recovery [3-5].

Other various measures such as use of preoperative medically trained clown for children, or interactive music therapy have been reported to allay preoperative anxiety but they did not relieve anxiety during mask induction of anaesthesia [6-8].

A few novel equipments to avoid 'mask fear' for the inhalation induction in children have been reported. Mahajan et al. [9] introduced a whistle fits into the open tail end of the reservoir bag that it blow only when patients breath from the bag. In Jagannathan's report [10], children were encouraged to breath through the mouth piece that is attached to breathing bag. These two devices, however, can be used only in connection with anaesthesia machine in the operating room.

We deviced a new, simple and inexpensive portable inhalational induction equipment that can be used in the preanaesthetic induction area for the paediatric patients. The objective of this clinical study is to introduce the new device and approve the clinical feasibility by comparing variables with that of the conventional inhalational induction method.

We hypothesized that the portable inhalational induction device will provide more co-operative and faster induction with the help of parents in the preanaesthetic induction area than the conventional inhalational induction in operation room with attending parents dressed in 'mask and gown.'

The primary outcome is the frequency of co-operative inhalation via a mask. The secondary outcomes are anxiety score on mask introduction, mask acceptance score and parent satisfaction with the inhalational induction method of their children.

These variables were compared between three methods of inducing anaesthesia: a portable inhalational induction device with $\mathrm{N}_{2} \mathrm{O}$ inhalation followed by sevoflurane inhalation or with sevoflurane inhalation in preanaesthetic induction area and a conventional inhalational induction in the operating room.

\section{Materials and Methods}

After the ethics committee of our institution approved this study, written informed consent was obtained from the parents of the subjects. Paediatric patients who were scheduled for simple elective surgery and satisfied the inclusion criteria were enrolled. Inclusion criteria were age between 30 and 95 months old age, body weight less than $35 \mathrm{~kg}$ and ASA class 1 or 2 . Children were excluded from the study if there was evidence of a reactive airway, an upper respiratory tract infection, the use of a medication known to affect cardio-respiratory function.

Forty-five patients were assigned using a computer generated random number table to one of three regimens by one of the investigators, who did not participate in the induction of anaesthesia. The treatments were: inhalational induction in the preanaesthetic induction area using the portable inhalational induction device with $\mathrm{N}_{2} \mathrm{O}$ followed by sevoflurane ( $\mathrm{PD} \mathrm{N}_{2} \mathrm{O}$ sevo group, $\mathrm{n}=15$ ) ; or with sevoflurane (PD sevo group, $\mathrm{n}=15$ ); conventional inhalational induction in the operating room with an attending parent (control group, $\mathrm{n}=15$ ).

One anaesthetist administered inhalational induction to all patients and did not participate in assessing the variables. The procedure was explained and demonstrated for the patients and their parents in the preanaesthetic induction area on the day of the operation. A trained research nurse blinded to the purpose of this study recorded the variables during anaesthesia.

The preanaesthetic induction area was continuous with the reception area and complied with standards for an anaesthetizing location, including the availability of suction, oxygen delivery, positive pressure ventilation and monitoring (anaesthesia machine) and resuscitative drugs and equipment. Gas samples were obtained from the breathing zone of the anaesthetist during ten simulated inductions using a portable inhalational induction device before the study was commenced. During each induction simulation, three gas samples were obtained at $90 \mathrm{~s}$ intervals.

The portable inhalational induction device consists of a face mask, a T-shaped connector containing two one-way valves, adaptors, a corrugated tube, a Y-connector, two on-off valves and two 51 reservoir bags (Fig. 1). The two one-way valves of the connector were obtained from a baby resuscitator (Ambu Baby Resuscitator, Ambu International A/S, Denmark) and maintained uni-directional flow from the reservoir bags to the patient, thus preventing re-breathing of exhaled gas. Gas flow from the reservoir bags to the corrugated tube was opened using the on-off valve (Jaqno siphon, ${ }^{\circledR}$ Jaqno Co., Gwangmeung, Korea) located between the reservoir bag and the Y-connector.

The anaesthesia machine (Ohmeda, Madison, WI) was primed with 8 vol\% sevoflurane in an oxygen mixture at a flow rate of 4 $\mathrm{L} / \mathrm{min}$ for $5 \mathrm{~min}$. This gas mixture was used to fill one reservoir bag for the $\mathrm{PD} \mathrm{N}_{2} \mathrm{O}$-sevo group and two reservoir bags for the $\mathrm{PD}$ sevo group. For the PD $\mathrm{N}_{2} \mathrm{O}$-sevo group, the second of the two reservoir bags was filled with $50 \% \mathrm{~N}_{2} \mathrm{O}$ in oxygen using another anaesthesia machine that had been primed with $\mathrm{N}_{2} \mathrm{O}$ $(2 \mathrm{~L} / \mathrm{min})$ and $\mathrm{O}_{2}(2 \mathrm{~L} / \mathrm{min})$ for $5 \mathrm{~min}$. Concentrations of $\mathrm{N}_{2} \mathrm{O}$ 


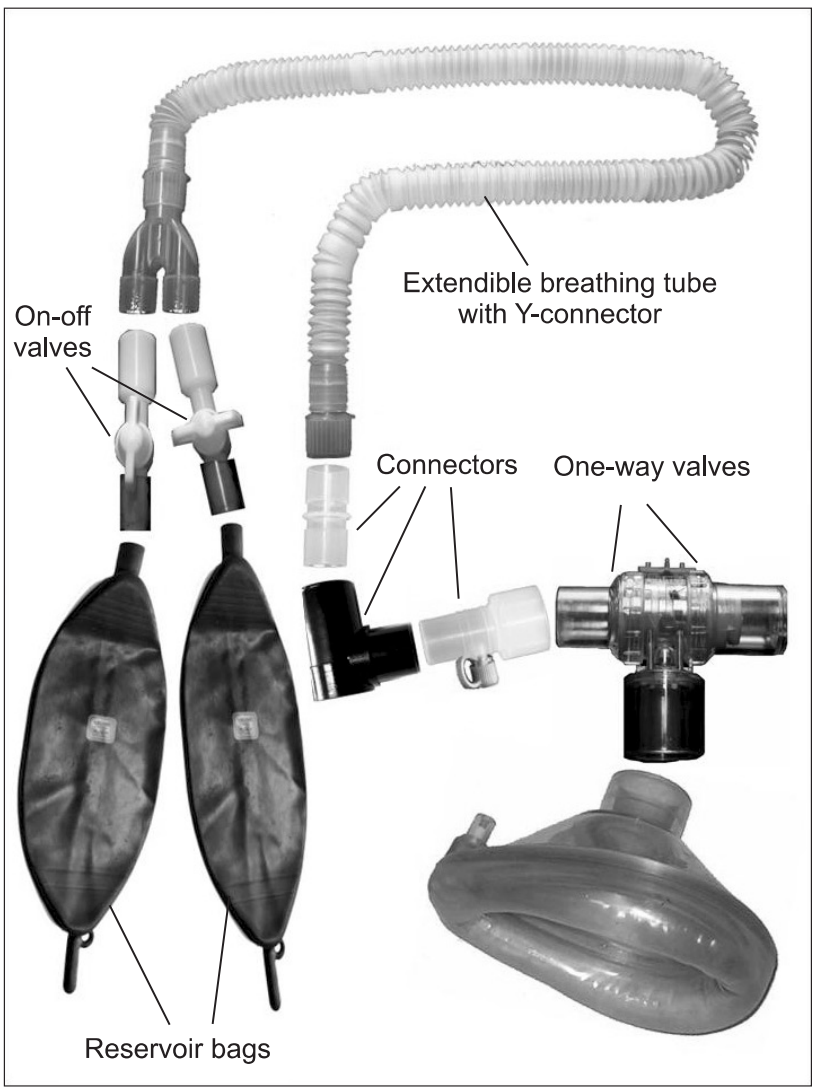

Fig. 1. Composition of the portable inhalational induction device. The portable inhalational induction device comprises a facemask, a T-shaped connector containing two uni-directional valves, three connectors, one extensible corrugated breathing tube, one Y-connector, two on-off valves, and two $5 \mathrm{~L}$ reservoir bags.

and sevoflurane during filling and discharging of the reservoirs were measured 15 times for each group before the study using continuous gas analysis equipment (Datex-Ohmeda S/5; DatexOhmeda Inc., Louisville, CO).

The anxiety state of the patients was evaluated when they arrived at the preanaesthetic induction area and when they were introduced to the mask used to induce anaesthesia according to the modified Yale Preoperative Anxiety Scale [11].

Sedation scores (0, awake/alert; 1 , sleep/responds appropriately; 2, somnolent/arouses to light stimuli; 3 , deep sleep/ arouses to deeper physical stimuli; and 4, unarousable to stimuli) [12] were determined when the patient arrived at the preanaesthetic induction area, when the patient was separated from the parents and when i.v. access was established.

Premedication was not administered. Children were reassured by the parents and the anaesthetist when they were fitted with the leads of portable electrocardiogram, non-invasive blood pressure and oxygen saturation monitors before commencement of inhalational induction.

On the day of surgery, the parents were asked to encourage their children to inhale the gas via a scented face mask and were informed that, if the patient did not comply, the mask would be forcibly applied by the anaesthetist and that this would induce mild sedation within two or three breaths.

Patients of $\mathrm{PD} \mathrm{N}_{2} \mathrm{O}$-sevo group $(\mathrm{n}=15)$ were encouraged by their parents and an anaesthetist to inhale the $50 \% \mathrm{~N}_{2} \mathrm{O} 10$ times and then to inhale the sevoflurane.

Patients of PD sevo group ( $\mathrm{n}=15)$ were encouraged by their parents and an anaesthetist to inhale the sevoflurane via a face-mask in the preanaesthetic induction room. When the patients did not respond to the name, they were transferred to the operating room, during which inhalation of sevoflurane was maintained via the portable inhalational induction device and patients were monitored continuously for the $\mathrm{PD} \mathrm{N}_{2} \mathrm{O}$-sevo and PD sevo groups.

For the control group $(\mathrm{n}=15)$, anaesthesia was induced in the operating room using a face mask connected to breathing circuit of anaesthesia machine with a parent in attendance.

Once anaesthesia was induced, an i.v. cannula was inserted and atropine $(0.02 \mathrm{mg} / \mathrm{kg})$ was injected. Vecuronium bromide $(0.1 \mathrm{mg} / \mathrm{kg})$ was administered to facilitate endotracheal intubation. General anaesthesia was maintained with $2-3$ vol\% sevoflurane and $50 \% \mathrm{~N}_{2} \mathrm{O}$ in $\mathrm{O}_{2}$ at a flow ratio of $1: 1$. Fentanyl $(1 \mu \mathrm{g} / \mathrm{kg})$ was used as an adjuvant analgesic during surgery if needed.

The duration of the anaesthesia induction was defined as the interval between commencement of encouragement to breathe the gas and the time at which the patient ceased to respond to his or her name assessed every 5 second.

Mask cooperation level during induction of anaesthesia was assessed ( 1 = easy, 2 = slightly resistant, 3 = markedly resistant) [13].

The number of co-operative inhalations and the total number of inhalations (co-operative plus inhalations commanded by parent) until the patient ceased to respond to his or her name were recorded.

Complications during anaesthesia were grouped into five main categories: coughing, laryngospasm, breath-holding, involuntary or purposeful movement of a limb and excessive salivation [14]. Bradycardia (heart rate $<100$ beats $/ \mathrm{min}$ ), hypoxia $\left(\mathrm{SpO}_{2}<95 \%\right)$ and respiratory depression (respiration rate $<8$ breaths $/ \mathrm{min}$ ) during anaesthesia were also recorded. The interval between discontinuation of sevoflurane inhalation and extubation was recorded.

Emergence delirium scores (1, no symptoms of emergence delirium; 2, mild symptoms such as occasional movement or crying and no need for restraint; 3 , marked symptoms of emergence delirium such as thrashing or a need for restraint or constant crying) [15] were recorded in the post-anaesthetic recovery room. Children were discharged from the recovery 
room at the discretion of the anaesthetist, based on discharge criteria [16], and the recovery time was noted.

Parents were asked to score their degree of satisfaction with the anaesthesia induction method and their child's recovery using a $100 \mathrm{~mm}$ linear visual analogue scale $(0=$ very dissatisfied, $100=$ very satisfied).

The sample size required for this study was estimated from a pilot study involving 10 patients per group. For a two-tailed $\alpha$ error of $5 \%$ and a $\beta$ error of $10 \%$, at least 13 patients per group were estimated to be required to detect a 2.6 times higher incidence of co-operative gas inhalation for the $\mathrm{PD} \mathrm{N}_{2} \mathrm{O}$-sevo group (median, range was $17.5,0-22$ ) compared with the control group (6, 0-14).

Table 1. Patient Characteristics and Duration of Surgery

\begin{tabular}{lccc}
\hline & $\begin{array}{c}\text { Control } \\
(\mathrm{n}=15)\end{array}$ & $\begin{array}{c}\text { PD sevo } \\
(\mathrm{n}=15)\end{array}$ & $\begin{array}{c}\mathrm{PD} \mathrm{N}_{2} \mathrm{O} \text {-sevo } \\
(\mathrm{n}=15)\end{array}$ \\
\hline Age (months) & $66(30-91)$ & $59(30-85)$ & $63(36-94)$ \\
Gender (M/F) & $8 / 7$ & $8 / 7$ & $9 / 6$ \\
Weight (kg) & $21(4.3)$ & $19(3.8)$ & $21(4.4)$ \\
$\begin{array}{l}\text { Duration of surgery } \\
(\text { min) }\end{array}$ & 36.6 & 38.3 & 36.6 \\
\hline
\end{tabular}

Values are expressed as the median (range), numbers or mean (SD). Control: conventional inhalational induction, PD sevo: inhalational induction with sevoflurane from a portable inhalational induction device, $\mathrm{PD} \mathrm{N}_{2} \mathrm{O}$-sevo: inhalational induction with $\mathrm{N}_{2} \mathrm{O}$ followed by sevoflurane from a portable inhalational induction device. $\mathrm{P}>0.05$.
Continuous data such as age, weight, time, inhalation frequencies and gas concentration were analysed using an oneway ANOVA followed by a least significant difference (LSD) for multiple comparisons. Gender distributions were analyzed by the Chi-squared test. Scores were analysed using the Kruskal-Wallis test followed by Bonferroni method for multiple comparisons. Statistical significance was defined as $\mathrm{P}<0.05$.

\section{Results}

Patient characteristics and duration of the operation were similar for all three groups (Table 1). Inhalational induction was faster for the PD $\mathrm{N}_{2} \mathrm{O}$-sevo and $\mathrm{PD}$ sevo groups than for the control group $(\mathrm{P}<0.001$, Table 2$)$. Recovery time was shorter for the $\mathrm{PD}$ sevo group than for the control group $(\mathrm{P}=0.028$, Table 2$)$.

The frequency of co-operative inhalation and total number of gas inhalation during induction were higher in the $\mathrm{PD} \mathrm{N}_{2} \mathrm{O}$-sevo group than in the PD sevo and control groups $(\mathrm{P}<0.001$, Table 3$)$.

The transition to sevoflurane after inhalation of $\mathrm{N}_{2} \mathrm{O}$ was easily accomplished by all except one of the patients in the PD $\mathrm{N}_{2} \mathrm{O}$ sevo group. He initially refused to inhale $\mathrm{N}_{2} \mathrm{O}$ but did not exhibit discomfort when he inhaled sevoflurane after being forced by his parents to take 10 breaths of $\mathrm{N}_{2} \mathrm{O}$. One patient in the control group rejected co-operative inhalation.

Mask cooperation was better in the $\mathrm{PD} \mathrm{N}_{2} \mathrm{O}$-sevo group than in the control group $(\mathrm{P}=0.016$, Table 3$)$.

Table 2. Time Associated with Induction of Anaesthesia and Recovery (min)

\begin{tabular}{|c|c|c|c|}
\hline & Control $(n=15)$ & PD sevo $(n=15)$ & $\mathrm{PD} \mathrm{N}_{2} \mathrm{O}$-sevo $(\mathrm{n}=15)$ \\
\hline Induction & $5.8(4-10)$ & $4.5(3.5-6.3)^{*}$ & $4.3(3.3-5.3)^{*}$ \\
\hline Interval between discontinuation of sevoflurane and extubation & $12.3(8.3-14.8)$ & $10.5(5-16.5)$ & $8(5-15)$ \\
\hline Recovery & $48(42-73)$ & $42(25-68)^{*}$ & $47(33-60)$ \\
\hline
\end{tabular}

Values are expressed as the median (range). Control: conventional inhalational induction, PD sevo: inhalational induction with sevoflurane from a portable inhalation induction device, $\mathrm{PD} \mathrm{N} \mathrm{N}_{2} \mathrm{O}$-sevo: inhalational induction with $\mathrm{N}_{2} \mathrm{O}$ followed by sevoflurane from a portable inhalational induction device. ${ }^{*} \mathrm{P}<0.05$ vs. the control group.

Table 3. Frequency of Gas Inhalation during the Induction of Anaesthesia

\begin{tabular}{|c|c|c|c|}
\hline & Control $(\mathrm{n}=15)$ & PD sevo $(n=15)$ & $\mathrm{PD} \mathrm{N}_{2} \mathrm{O}$-sevo $(\mathrm{n}=15)$ \\
\hline Frequency of co-operative gas inhalation & $8(0-15)$ & $9(1-15)$ & $18(0-22)^{*, \dagger}$ \\
\hline Total frequency of gas inhalation (co-operative plus forcible) & $10(8-15)$ & $10(7-15)$ & $19(14-22)^{*, \dagger}$ \\
\hline Numbers of patients with mask co-operation score of 1,2 or 3 & $6,6,3$ & $8,4,3$ & $14,0,1^{*}$ \\
\hline Sedation score $(0-4)$, before induction & $0(0-0)$ & $0(0-0)$ & $0(0-0)$ \\
\hline , during separation & $3(2-3)$ & $3(2-3)$ & $3(2-3)$ \\
\hline , during i.v. access & $4(3-4)$ & $4(3-4)$ & $4(3-4)$ \\
\hline Anxiety scale (5-22), before induction & $13(6-21)$ & $10(5-20)$ & $14(5-22)$ \\
\hline , on mask application & $17(10-25)$ & $11(6-21)^{*}$ & $15(6-22)$ \\
\hline Numbers of patients with emergence delirium score of 1,2 or 3 & $0 / 6 / 9$ & $0 / 7 / 8$ & $0 / 8 / 7$ \\
\hline
\end{tabular}

Values are expressed as the median (range) or numbers. Control: conventional inhalational induction, PD sevo: inhalational induction with sevoflurane from a portable inhalational induction device, $\mathrm{PD} \mathrm{N}_{2} \mathrm{O}$-sevo: inhalational induction with $\mathrm{N}_{2} \mathrm{O}$ followed by sevoflurane from a portable inhalational induction device. ${ }^{*} \mathrm{P}<0.05$ compared with the control group. ${ }^{\dagger} \mathrm{P}<0.05$ vs. the $\mathrm{PD}$ sevo group. 
Table 4. Concentrations of $\mathrm{N}_{2} \mathrm{O}$ and Sevoflurane in the Reservoir Bags during Filling and Discharge

\begin{tabular}{lccc}
\hline & $\begin{array}{c}\text { Control } \\
(\mathrm{n}=15)\end{array}$ & $\begin{array}{r}\text { PD sevo } \\
(\mathrm{n}=15)\end{array}$ & $\begin{array}{c}\text { PD N } \mathrm{N}_{2} \mathrm{O}-\text { sevo } \\
(\mathrm{n}=15)\end{array}$ \\
\hline Filling (sevoflurane, vol\%) & & $8.2(0.0)$ & $8.1(0.0)$ \\
Discharge (sevoflurane, vol\%) & $8.0(0.0)$ & $7.9(0.1)$ & $7.8(0.1)$ \\
Filling $\left(\mathrm{N}_{2} \mathrm{O}, \%\right)$ & & & $50.9(0.9)$ \\
Discharge $\left(\mathrm{N}_{2} \mathrm{O}, \%\right)$ & & & $49.6(0.9)$ \\
\hline
\end{tabular}

Values are expressed as the mea (SD). Control: conventional inhalational induction, PD sevo: inhalational induction with sevoflurane from a portable inhalational induction device, $\mathrm{PD} \mathrm{N}_{2} \mathrm{O}$-sevo: inhalational induction with $\mathrm{N}_{2} \mathrm{O}$ followed by sevoflurane from a portable inhalational induction device.

The anxiety scores upon the introduction of the anaesthesia mask were lower for the PD sevo group $(\mathrm{P}=0.015)$ than for the control group.

No additional drugs (fentanyl or inotropics) were administered in any of the three groups.

One patient in the $\mathrm{PD} \mathrm{N}_{2} \mathrm{O}$-sevo group developed bradycardia (90 beats/min) just after transfer from the gurney to the operating table.

Complications such as cough, laryngospasm, breath-holding, involuntary or purposeful movement of a limb, excessive salivation, hypoxia $\left(\mathrm{SpO}_{2}<95 \%\right)$, or respiratory depression (respiration rate $<8$ breaths $/ \mathrm{min}$ ) during anaesthesia were not observed. There were no episodes of nausea, vomiting, airway irritability or shivering during the recovery period. Parent satisfaction score $(0-100)$ was higher for the PD $\mathrm{N}_{2} \mathrm{O}$-sevo group (median, range; 95, 80-100) than for the control group $(80,50-100)(\mathrm{P}=0.008)$.

The mean concentration of sevoflurane during filling and discharge did not differ between groups (Table 4).

\section{Discussion}

This clinical study is not primarily a study of the equipment itself but of place of induction (in the preanaesthetic area vs. operating room), parents possibilities to support (in the preanaesthetic area vs. operating room with mask and gown), sequential $\mathrm{N}_{2} \mathrm{O}$ and sevoflurane inhalation vs. sevoflurane.

In our study results, the frequency of co-operative gas inhalation was higher for the $\mathrm{PD} \mathrm{N}_{2} \mathrm{O}$-sevo group than for the $\mathrm{PD}$ sevo or the control groups. The co-operative gas inhalation via a mask is a form of an active participation of children and it was more likely in conditions when the children were willing to accept mask application with lower anxiety and when the $\mathrm{N}_{2} \mathrm{O}$ was inhaled first.

The control group patients exhibited an increasing degree of anxiety while they were moving into the operating room and showed higher anxiety for the mask introduction than the patients in the PD sevo group. The portability of the inhalational induction device is clinically important as it allows induction in the preanaesthetic induction area in more co-operation with parents present compared to the conventional inhalational induction that is performed in the unfamiliar operating room with passive parents dressed in hat and gown, eventually face mask.

The mask cooperation was better in the $\mathrm{PD} \mathrm{N}_{2} \mathrm{O}$-sevo group than in the control group. The transition to sevoflurane after inhalation of $\mathrm{N}_{2} \mathrm{O}$ was easily accomplished by all except one patient in the $\mathrm{PD} \mathrm{N}_{2} \mathrm{O}$-sevo group. Mild sedation by the $\mathrm{N}_{2} \mathrm{O}$ may have reduced the incidence of rejection to sevoflurane and contributed to the greater satisfaction of parents of the PD $\mathrm{N}_{2} \mathrm{O}$-sevo group patients relative to that of the parents of control group patients.

The concept of using $\mathrm{N}_{2} \mathrm{O}$ inhalation to induce light sedation [17] has several advantages, including rapid onset of sedation, the ability to titrate the flow ratio according to its effect, analgesia and rapid recovery from sedation [17]. However, successful application of $\mathrm{N}_{2} \mathrm{O}$ depends on the patient's willingness to accept placement of the mask. Encouragement of patients to accept mask by parents in the preanaesthetic induction area may help to inhale $\mathrm{N}_{2} \mathrm{O}$ more co-operatively than in the operating room.

The absence of airway complications and hypoxia during anaesthesia shows that the portable inhalational induction device is clinically acceptable. Assembly of the device requires only 1.5-2 min after a short period of becoming acquainted with the assembly procedure.

The mean level of sevoflurane in the preanaesthetic induction area was below the 0.5 parts per million (ppm) limit at all times $(0.2 \pm 0.07 \mathrm{ppm})$, as was the $\mathrm{N}_{2} \mathrm{O}$ level $(11.4 \pm 2.0 \mathrm{ppm}$; threshold limit $=25 \mathrm{ppm})$ [18].

The anaesthetist who performed the induction knew which method was to be used but did not participate in measuring variables. A disadvantage of the portable inhalational induction device is that the reservoir bag has to be pre-filled with gas.

In conclusion, the portable inhalational induction device allows faster induction in co-operation with parents present in the preanaesthetic induction area compared to conventional inhalational induction method with parents present in unfamiliar operating room.

\section{References}

1. Ariffin SA, Whyte JA, Malins AF, Cooper GM. Comparison of induction and recovery between sevoflurane and halothane supplementation of anaesthesia in children undergoing outpatient dental extractions. Br J Anaesth 1997; 78: 157-9.

2. Kim YH, Jeong YS, Choi GS, Park SI, Son SC. Effects of sevoflurane 
and desflurane on respiratory mechanics after tracheal intubation in children. Korean J Anesthesiol 2009; 57: 714-8.

3. Arai YC, Fukunaga K, Hirota S. Comparison of a combination of midazolam and diazepam and midazolam alone as oral premedication on preanesthetic and emergence condition in children. Acta Anaesthesiol Scand 2005; 49: 698-701.

4. Riva J, Lejbusiewicz G, Papa M, Lauber C, Kohn W, Da Fonte M, et al. Oral premedication with midazolam in paediatric anaesthesia. Effects on sedation and gastric contents. Paediatr Anaesth 1997; 7: 191-6.

5. Cohen IT, Drewsen S, Hannallah RS. Propofol or midazolam do not reduce the incidence of emergence agitation associated with desflurane anaesthesia in children undergoing adenotonsillectomy. Paediatr Anaesth 2002; 12: 604-9.

6. Golan G, Tighe P, Dobija N, Perel A, Keidan I. Clowns for the prevention of preoperative anxiety in children: a randomized controlled trial. Paediatr Anaesth 2009; 19: 262-6.

7. Vagnoli L, Caprilli S, Robiglio A, Messeri A. Clown doctors as a treatment for preoperative anxiety in children: a randomized, prospective study. Pediatrics 2005; 116: e563-7.

8. Kain ZN, Caldwell-Andrews AA, Krivutza DM, Weinberg ME, Gaal D, Wang SM, et al. Interactive music therapy as a treatment for preoperative anxiety in children: a randomized controlled trial. Anesth Analg 2004; 98: 1260-6.

9. Mahajan R, Grover VK, Kumar S. Whistle: another method of induction of pediatric anesthesia. Paediatr Anaesth 2007; 17: 905-6.

10. Jagannathan $\mathrm{N}$. An alternative method of induction for the child with 'mask fear'. Paediatr Anaesth 2008; 18: 337.

11. Kain ZN, Mayes LC, Cicchetti DV, Bagnall AL, Finley JD, Hofstadter
MB. The Yale Preoperative Anxiety Scale: how does it compare with a "gold standard"? Anesth Analg 1997; 85: 783-8.

12. Malviya S, Voepel-Lewis T, Tait AR, Merkel S, Tremper K, Naughton N. Depth of sedation in children undergoing computed tomography: validity and reliability of the University of Michigan Sedation Scale (UMSS). Br J Anaesth 2002; 88: 241-5.

13. Epstein RH, Mendel HG, Witkowski TA, Waters R, Guarniari KM, Marr AT, et al. The safety and efficacy of oral transmucosal fentanyl citrate for preoperative sedation in young children. Anesth Analg 1996; 83: 1200-5.

14. Ho KY, Chua WL, Lim SS, Ng AS. A comparison between singleand double-breath vital capacity inhalation induction with $8 \%$ sevoflurane in children. Paediatr Anaesth 2004; 14: 457-61.

15. Kain ZN, Caldwell-Andrews AA, Maranets I, McClain B, Gaal D, Mayes LC, et al. Preoperative anxiety and emergence delirium and postoperative maladaptive behaviors. Anesth Analg 2004; 99: 164854.

16. Malviya S, Voepel-Lewis T, Ludomirsky A, Marshall J, Tait AR. Can we improve the assessment of discharge readiness?: a comparative study of observational and objective measures of depth of sedation in children. Anesthesiology 2004; 100: 218-24.

17. Hulland SA, Freilich MM, Sandor GK. Nitrous oxide-oxygen or oral midazolam for pediatric outpatient sedation. Oral Surg Oral Med Oral Pathol Oral Radiol Endod 2002; 93: 643-6.

18. Mierdl S, Byhahn C, Abdel-Rahman U, Matheis G, Westphal K. Occupational exposure to inhalational anesthetics during cardiac surgery on cardiopulmonary bypass. Ann Thorac Surg 2003; 75 1924-7. 